\title{
Simulating agricultural land-use adaptation decisions under changing climate using multi-agent system model in the Upper East Region of Ghana
}

\author{
$\underline{\text { M.L. Amadou }}^{\mathrm{a}}$ and G.B. Villamor \\ ${ }^{a}$ Kwame Nkrumah University of Science and Technology(KNUST), Kumasi, Ghana \\ ${ }^{b}$ Center for Development Research (ZEF), University of Bonn, Germany \\ Email:1aouali@gmail.com
}

\begin{abstract}
This paper explores the application of the multi-agent system (MAS) models for understanding of agricultural adaptation to climate changes. To date, only very few studies empirically operationalise decision making on adaptation based on farmers' perception of climate variability in the MAS. The challenge particularly lies on how to isolate planned adaptation within a large traditional number of autonomous adaptation practices. This paper focuses on the implementation of a MAS approach for investigating the traditional adaptive strategies in the dryland areas in the Upper East Region of Ghana by considering farmers' perception of climate change and variability. In order to achieve this, Land Use Dynamic Simulator (LUDAS) approach was adapted and modified by integrating the two step-decision making sub-models. This modified version of LUDAS called SKY-LUDAS (referring to the communities where it was implemented: Sirigu-Sumbrungu-Kandiga-Yuwa) was constructed to capture the empirical heterogeneity of farm household agents and landscape agents (biophysical environment), and also to explicitly simulate interactions between these two agent types. From the results of the multivariate statistical methods, three farm household agent groups were identified. Also the factors explaining the decision of these three household agent groups on the choice of the six identified land-use types were analysed. Two sub-models were developed and calibrated for implementing the two-step decision making sub-models: Perception-of-Climate-Change and Adaptation Choice strategies. Simulation results of SKY-LUDAS suggested that the land-use behaviour in the study area reflects a tendency of subsistence farming. In terms of farm-households' livelihood strategy, especially the structure of the gross income, there was a growing contribution of rice and groundnut. Also the pattern of the gross income under the scenario of perception on climate change (PCC) showed explicitly the contribution of the adaptation options in the households' livelihood strategy. Accordingly, SKY-LUDAS has revealed a gradual shift among land-use types from traditional cereals farming to the cultivation of groundnuts, rice, maize and soybean. Based on the two-step decision mechanism implemented in SKY-LUDAS, groundnut in mono-cropping has emerged as coping measure. Therefore, this research has a merit of contributing to answer the critical question on whether some adaptation practices are stimulated by climate or other factors.
\end{abstract}

Keywords: Heterogeneous farm households, perception on climate change, decision making, land-use adaptation 


\section{INTRODUCTION}

Land-use change is driven by synergistic factors of resource scarcity leading to an increase in the pressure of production on resources, changing opportunities created by markets, outside policy intervention, loss of adaptive capacity and changes in social organisation and attitudes (Lambin et al., 2003). Heterogeneity is one of the factors of the complexity of land-use change especially in African contexts where it is considered as a norm (Berhan et al., 2011). Such heterogeneity from farming systems to land-use decisions through cropping systems reflects the livelihood strategy. It is widely admitted that climate represents a powerful environmental constraint on many human activities (Houghton et al., 2001). Due to its complexity related to the interaction between the human and physical environment, agricultural land-use system in the context of climate change calls for multidisciplinary analyses (Veldkamp \& Lambin, 2001). One of the operationalised tools of this approach is Multi-Agent System (MAS). A growing number of MASs were built for analysing farm decision making in agricultural land-use system, especially in simulating the adaptation of agricultural land-use to climate change in order to understand the interactions between the heterogeneous population and the agro-ecological resources (Schreinemachers \& Berger, 2011, Troost et al., 2012). In such circumstances, previous studies suggested that in order to improve estimates of climate impacts on agricultural land use and contribute efficiently to adaptation research, there is a need to know more about how farmers perceive climate and how they respond, in both the short-and long-term, to variable climate conditions, including the magnitude and frequency of extreme conditions (Smit et al., 1996). This research focuses on (1) the exploration of the main agricultural land-use change in the study area and (2) the implications of farmers' decision in agricultural land-use adaptation to climate change and variability.

\section{METHODS}

\subsection{Study area and data analysis}

The study area is located within Atankwidi catchment in the Upper East Region of Ghana between Navrongo and Bolgatanga. It is geographically located between latitude $10^{\circ} 50^{\prime} 41^{\prime \prime}-11^{\circ} 00^{\prime} 35^{\prime \prime} \mathrm{N}$, and longitude $1^{\circ} 03^{\prime} 47^{\prime \prime}$ - $0^{\circ} 53^{\prime} 02^{\prime \prime} \mathrm{W}$. Within the catchment, the study focused on the area $\left(192 \mathrm{~km}^{2}\right)$ populated by four villages: Sumbrungu, Sirigu and Kandiga and Yuwa. Agriculture is the main economic activity in the area. Many households are engaged in activities such as handicrafts, trading, wood cutting and livestock which constitute the main source of cash income. Most available lands are used for small-scale agriculture in the rainy season. The area is covered by scattered compound houses that are usually surrounded by farmland of mixed cropping of cereals, groundnuts and rice. Some uncultivated patches are usually scattered within the croplands, serving as grazing land for the local livestock. In addition to the aforementioned characteristics, the area was chosen because it is located in one of the poorest regions of Ghana, where research on the impact of policy interventions on local socio-economic and agro-ecological conditions could be of high importance, especially for supporting sustainable improvement of local living conditions. The data were collected using a semi-structured household questionnaire between January and April 2013. Both qualitative and quantitative data were collected on the following topics: (1) farming systems, (2) farmers' perception of climate change and variability and (3) adaptation strategies. A total of 186 households distributed among the four villages were randomly selected and surveyed. The sample was composed of $15 \%$ female headed households of which $66 \%$ of them are widows, while $85 \%$ are male headed households. As key decision markers within the house, the household heads were interviewed. Most of them fall within the range of age 30 to 76. From these data, statistical approaches such as Principal Component Analysis and K-means cluster were used to derive agent typologies. Then specific behaviour with respect to land use of each agent group was determined by using multinomial logistic regression (MNL) analysis. MNL and binary logistic regression analysis serve respectively in assessing the choice of adaptation options and the good perception of climate change and variability through procedure called two-step decision making and integrated in SKYLUDAS.

\subsection{SKY-LUDAS: model description}

The MAS model was based on the LUDAS framework (Le et al., 2008). The ODD protocol (Overview, Design concept, and Details) (Grimm et al., 2006, 2010) of LUDAS model is explicitly described in Le et al. (2010), and Villamor et al. (2014). SKY-LUDAS emphasises on human decision making by integrating the two-step decision making used to assess the implications of climate change perception in adaptation decision (Villamor 2012). Therefore, with respect to the ODD+D protocol (Müller et al., 2013), SKY-LUDAS was described in more details in Amadou (2015). 
Amadou and Villamor, Simulating agricultural land-use adaptation decisions under changing climate...

\section{Overview}

Purpose, agents, state variables and scales: The purpose of SKY-LUDAS was to explore the complex dynamics of agro-ecological systems based on how households' farming systems cope with climate change and variability in the study area. The model examines the relationship between population growth (household agent patterns), the agro-ecosystem (through land-use patterns) and farmers' adaptation to climate change and variability. There are two types of agents: (1) human agents are represented by the individual farm households. The state variables of human agents are represented by several livelihood indicators which guide the livelihood strategies by considering their assets (Campbell et al., 2001). The variables include social identity; human resources; land resources; financial resources; physical capital; and policy access. (2) landscape agents are represented by individual congruent land patches with resolution of $30 \mathrm{~m}$ as corresponding to the GIS-raster layers of biophysical spatial variables (e.g. land cover). The following variables are also related to landscape agents: spatial proximity (e.g. distance from house to the main river); landscape vision which is a sphere of influence for household agent (Le et al., 2008). The policy factors (subsidy on farm inputs, information on weather and climate change) are considered externally with regard to the boundary of the modelled system in order to define different scenarios and policy management.

Process overview and scheduling: one time step represents one year. The model runs with annual time basis over a period of 20 years. The main time loop of the simulation program, called annual production cycle includes sequential steps which are agent-based and integrated with patch-based processes (Villamor et al., 2014). Basically the main steps specified by SKY-LUDAS during a simulation run include: (1) set-up initial state of the system, (2) update agent and patch attributes, (3) adopt behavior parameters, (4) farmland choice, (5) other sources of income, (6) update changes in agent and patch attributes, (7) categorise households, (8) translate annual land-use changes, (9) create new agents and (10) calculate crop productivity. As SKYLUDAS is a stochastic model (Le et al., 2012), the simulations were replicated 5 times for each mechanism in order to face uncertainty in the model outputs.

Details

Input: Data and parameters were parameterized and calibrated for each sub-model (Table 1).

Table 1. External input and sub-models in SKY-LUDAS model.

\begin{tabular}{|c|c|c|}
\hline Sub-model & Parameter & Data source \\
\hline Land-use choice & $\begin{array}{l}\text { Characteristics of farm plot user (e.g. age, } \\
\text { education, status, income, etc.), natural land } \\
\text { attributes (e.g. elevation, slope, soil fertility, etc.), } \\
\text { policy related variables (extension, subsidy, etc.) }\end{array}$ & \multirow{6}{*}{$\begin{array}{l}\text { Field survey } 2012 \text { and GIS- } \\
\text { based calculations }\end{array}$} \\
\hline Mixed cereals yield & $\begin{array}{l}\text { Labour, agrochemical inputs, organic matter inputs, } \\
\text { livestock index, soil fertility, plot area, flow } \\
\text { accumulation and slope gradient of the plot. } \\
\text { Early millet: } 1160 \mathrm{~kg} \cdot \mathrm{ha}^{-1} \cdot \mathrm{y}^{-1} \text {; late millet: } 1490 \\
\mathrm{~kg} \cdot \mathrm{ha}^{-1} \cdot \mathrm{y}^{-1} \text {; and sorghum: } 1514 \mathrm{~kg} \cdot \mathrm{ha}^{-1} \cdot \mathrm{y}^{-1}\end{array}$ & \\
\hline Groundnut yield & $\begin{array}{l}\text { Labour, livestock index, soil fertility, plot area, flow } \\
\text { accumulation and slope gradient of the plot } 1086 \\
\mathrm{~kg} \cdot \mathrm{ha}^{-1} \cdot \mathrm{y}^{-1}\end{array}$ & \\
\hline Rice yield & $\begin{array}{l}\text { Labour, agrochemical inputs, livestock index, soil } \\
\text { fertility, plot area, flow accumulation and slope } \\
\text { gradient of the plot. } 1257 \mathrm{~kg} \cdot \mathrm{ha}^{-1} \cdot \mathrm{y}^{-1}\end{array}$ & \\
\hline $\begin{array}{l}\text { Perception of climate } \\
\text { change }\end{array}$ & $\begin{array}{l}\text { Characteristics of farm plot user (e.g. age, gender, } \\
\text { etc.), local agro-ecological setting of the household } \\
\text { (e.g. elevation, slope, etc.), policy related variables } \\
\text { (information on weather and climate). Perception as } \\
\text { binary outcome with value } 1 \text { or } 0 \text {. }\end{array}$ & \\
\hline $\begin{array}{l}\text { Land-use adaptation } \\
\text { choice }\end{array}$ & $\begin{array}{l}\text { Characteristics of farm plot user (e.g. age, } \\
\text { education, status, income, etc.), natural land } \\
\text { attributes (e.g. wetness index, soil fertility, etc.), } \\
\text { policy related variables (extension, subsidy, etc.) }\end{array}$ & \\
\hline
\end{tabular}


Amadou and Villamor, Simulating agricultural land-use adaptation decisions under changing climate...

Sub-models

In addition of the land-use choice sub-models developed in LUDAS framework (Le et al., 2008, Villamor et al., 2014), two-step decision making sub-models were developed for SKY-LUDAS for simulating land-use adaptation. This procedure was designed in accordance with the decision-making approach developed in LBLUDAS to capture process-based decision-making (Villamor, 2012). Accordingly, the Perception-ofClimate-Change and the Adaptation-Choice sub-models were integrated in the decision module of LUDAS particularly within the Farmland-Choice procedure as a household decision-making mechanism (Le et al., 2008). The first step simulates farmers' perception of climate change while the second step simulates the choice of land-use adaptation strategies if only the farmer has perceived climate change. These two steps decision-making routines developed under decision programme as two different procedures are taken by each household agent in each time step, independently of its agent group.

First step: this step was developed based on the results of binary logistic regression. The probability $P \_h i j-$ perception is a binary outcome of Perception-of-Climate-Change represented in the model through a dummy variable taken value 1 when the farmer has perceived climate change and 0 otherwise. When the value of probability $\mathrm{P}$ hij-perception is 0 , the decision programme skips the adaptation procedure to the common Farmland-Choice routine: in this case, only the baseline runs for a given household agent. In contrast, when

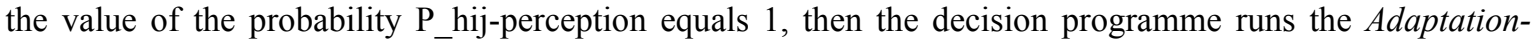
Choice routine to compute the probability of choosing an adaptation option. Suggesting, all the household agents with good perception of climate change are engaged in the multiple choice procedure.

Second step: the second step sub-module is designed in the model based on the results of the m-logit through the probability of five following adaptation choices: Crop-livestock integration; Irrigation; Maize farming; Soybean farming and No adaptation. The last option (No adaptation) was used as base category in the m-logit analysis. When the household chooses a particular adaptation option, then the option is executed in the FarmlandChoice routine especially during the moving phase. This second step involves many indicators especially labour force to make up a particular selected option.

\subsection{Scenario}

Based on the identified range of land-use related factors and livelihood indicators, three specific scenarios were systematically tested: Business as usual scenario (Baseline); Perception of climate change and variability (PCC) scenario and No perception of climate change and variability (NO-PCC) scenario.

\section{Business as usual scenario}

The baseline setting corresponds to the business as usual where the decision-making programme follows the empirical land-use choice model as the benchmark (Le et al., 2008). Existing main agricultural land-uses were simulated based on the agent's landholdings over a period of 20 years with changes to biophysical conditions based on the dynamics and population increase.

\section{Perception of climate change and variability scenario (PCC)}

The PCC scenario was set in the programme in addition of the baseline scenario. Accordingly, this scenario goes through two procedures (see section 2.2): first step and second step. As explained in the description of the two-step decision mechanism, the probability of farmers' perception with binary outcome in the first step and the available labour budget determine the implementation of the second step. Then, the choice of each option is based on the relative probabilities of land-use adaptation options calculated for each household agent.

\section{No perception of climate change and variability scenario (NO-PCC)}

Using the baseline alone and the two-step decision making in simulating land-use adaptation is not enough to give the understanding of the implications of climate change (Perception-of-Climate-Change) in the adaptation choice (AdaptationChoice). For a better understanding of the two-step decision mechanism, the scenario of No perception (NO-PCC) was developed in the decision programme. This scenario consisted of stopping the routine of the first step in the PCC scenario. By doing so, no more restriction related to the Perception-of-Climate-Change existed again in the decision programme. In this case, the decision programme runs the second step (AdaptationChoice) for all the farm household agents. Only labour budget can limit a household agent in implementing a selected land-use adaptation option. 
Amadou and Villamor, Simulating agricultural land-use adaptation decisions under changing climate...

\subsection{Validation}

For the model validation, the study focused on expert opinion (Villamor et al., 2012) especially on previous modelling efforts undertook in the area and the role playing game (Suphanchaimart et al., 2005) to better understand farmers decision making regarding land-use adaptation. Therefore, twenty role games were run in the purpose of validating the simulation results of SKY-LUDAS. The findings of the model required more participatory processes to investigate farmers' behavior in terms of their decision to land-use change. The games were implemented in the same area. Also, among farmers with good perception of climate change and variability, twelve farmers were selected for individual game to validate land-use adaptation simulations of SKY-LUDAS especially when using the PCC scenario. Four scenarios were used during this individual game: baseline, early onset of rains, delay in onset of rains and drought frequency during the rainy season.

\section{RESULTS AND DISCUSSION}

\subsection{Decisions to agricultural land-use change adaptation}

Agricultural land-use cultivated area

With respect to Figure 1.a, a clear increase of cultivated area of mixed cereals was simulated by SKYLUDAS, regardless of the three scenarios. Also, a clear rapid increase was observed in the trend of the simulated cultivated area of rice up to the year 7 then it became relatively constant over time (Figure 1.b). the reason behind this land-use pattern is the land suitability of this crop, because even though rice can be grown on uplands during the rainy season, the suitable areas are mostly located along the river side which are limited (Amadou, 2015). Groundnuts also showed a slight increasing trend in the cultivated area, which became important in the last four years (Figure 1.c). Given the aforesaid, the agricultural land-use behaviour reflected a tendency of subsistence farming which is in line with the findings of the previous research in the study area (Schindler, 2009). Moreover, the increased food demand due to the rapid growing population is another factor of increasing the importance of improving productivity of land (Hageback et al., 2005). In the case of PCC scenario, household-agents do not emphasis on increasing the cultivated land area of mixed cereals; instead they are more involved in different alternatives for their livelihood strategy such as groundnuts or other adaptation options. This justified the lowest magnitude in terms of trend of cultivated area of mixed cereals (Figure 1a) with a lowest change of about 624 ha from year 1 (235 ha) to year 20 (859 ha). In contrast, this scenario (PCC) has the highest magnitude (Figure 1c) with a change of about 70 ha compared to the baseline ( $57 \mathrm{ha}$ ) in the cultivated area of groundnuts under PCC scenario where groundnuts were used as cash crop especially in the case of mono-cropping system. An opposite behaviour was observed in the case of rice (Figure 1b) suggesting that even if this crop is grown as cash crop the reason behind would be stimulated by another purpose different from climate stimuli. Accordingly, farmers' perception of climate change and variability lead to change from mixed cereals to groundnuts, compared to some very minor difference in rice area.

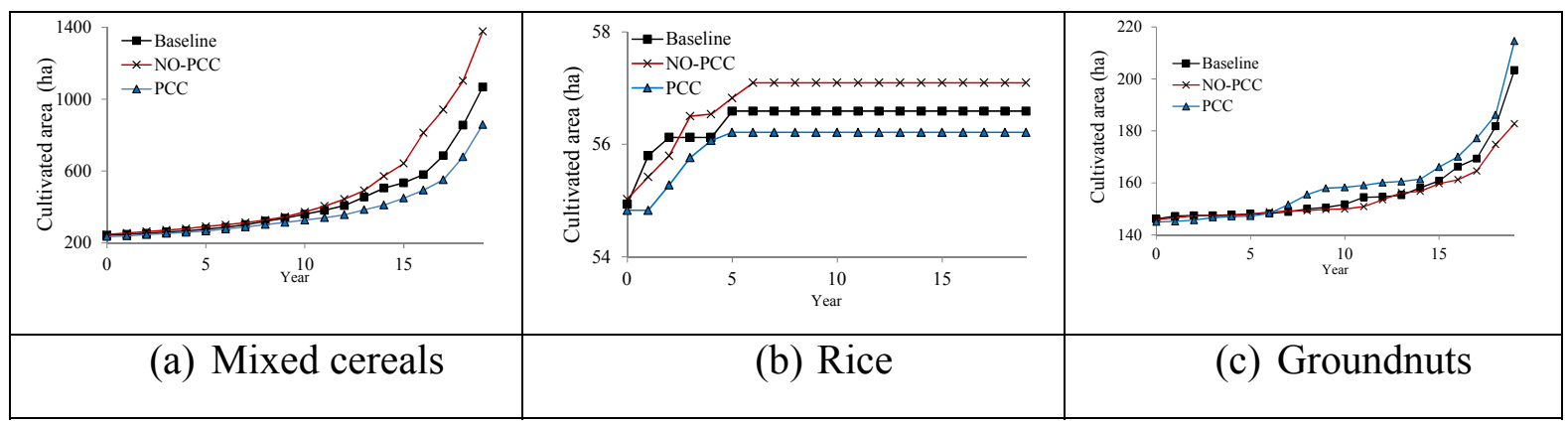

Figure 1. Implications of climate change and variability in the decision of adopting agricultural land-use change.

\section{Agricultural land-use income structure}

Due to its percentages, mixed cereals represent the main income contribution (Figure 2a). This confirms again in addition to the extensiveness and the subsistence oriented behaviour of agricultural land-use system in the study area which is supported by the highest magnitude of the income contribution trend of mixed cereals under baseline scenario. An important point is that even though the cultivated area of the mixed cereals is increasing (Figure 1a), but in terms of income contribution, this land-use type is experiencing a downward trend over time, which suggests also a change in livelihood strategy. Another interesting point is also the lowest magnitude of the scenario PCC which indicates that the income contribution of mixed cereals- 
based is less important for farmers with good perception of climate change and variability. The reduction of the income contribution percentage between the first and the twentieth year of mixed cereals under PCC scenario is the greatest (-5\%) comparing to the NO-PCC and baseline scenarios with respectively - $4 \%$ and $3 \%$ (Figure 2a). As a result, the better farmers' climate perception is, the less they are involved in cultivating mixed cereals the more they are involved in other alternatives.

With respect to Figure $2 b$, the increase of the income contribution of rice under NO-PCC scenario is the greatest $(0.5 \%)$ in comparison with the increase of the percentage of rice income under PCC and baseline scenarios, with both an increase of $0.2 \%$. In accordance with the above, it was explicitly shown that farmers with good awareness of climate change are more involved in choosing groundnuts as livelihood strategy than rice. This was due to the fact that rice farming was more demanding in terms of labour, water, farm inputs and care, and for these reasons this land-use type (rice) could not be the choice of the majority of small-scale farmers as a diversification option. Despite these factors, a net difference was observed in the increase of percentage of income contribution of groundnut under PCC scenario (Figure 2c). Accordingly, the change of the income contribution of this land-use type under PCC scenario is the greatest with $5 \%$ comparing to the NO-PCC and baseline scenarios with respectively $4 \%$ and $3 \%$.

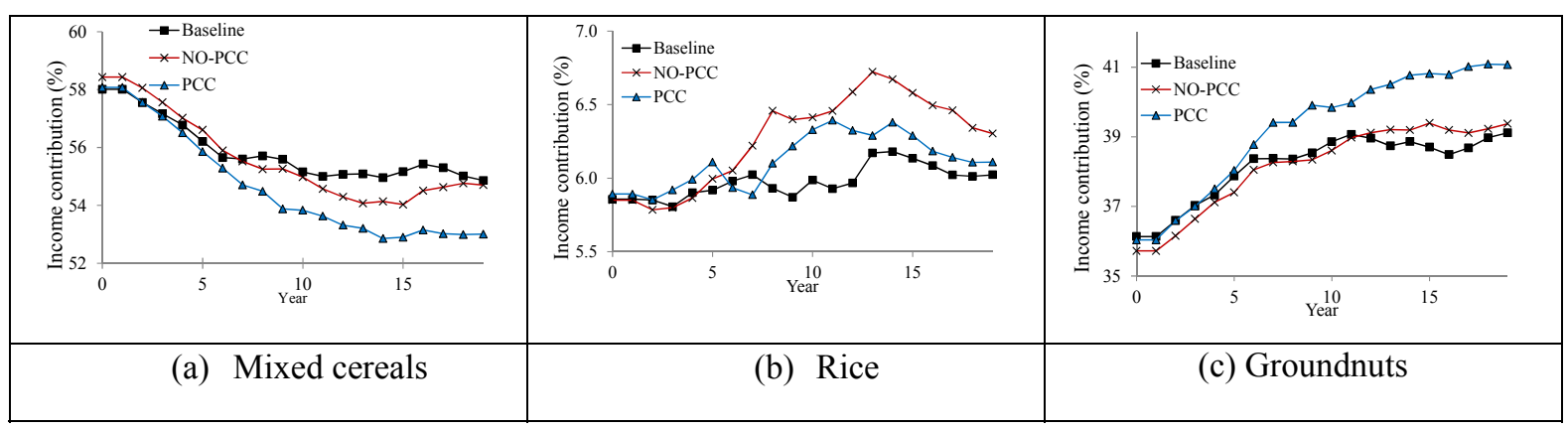

Figure 2. Implications of climate change and variability in the income structure of the main agricultural land uses.

\subsection{Validation}

In the agricultural land-use system of the study area, the cultivated area of mixed cereals dominated (Figure 1a), but its contribution to income structure of the household revenue is decreasing (Figure 2a) unlike rice and groundnuts (Figure 2b, 2c). This is supported by Schindler (2009) who implemented an agent-based model in the same region and came out with the following conclusion: "A gradual shift among land-use types from traditional cereals farming to cultivation of rice and groundnuts was observed during the last decades". Therefore, this research found a good indicator of resilience for the agricultural land-use in the study area. The preliminary results of the role playing game (RPG) conducted with farmers with good perception of climate change and variability show that traditional cereals (mixed cereals) constitute the main land-use system in the area while rice and groundnuts are the two land-uses with market value together with maize and soybean. The traditional cereals are used for the staple food and funerals performances. Therefore, this land-use type does not change too much. In normal situation of rainy season (baseline), groundnut is grown under mixed cropping and mono-cropping system. However in the scenarios of delay in onset of rains and drought frequency, it was observed that groundnut in mixed cropping disappears and farmers maintain mono-cropping system. The reason was that in the mixed groundnut, they usually grow the traditional variety of groundnut which has a long vegetative cycle. In the situation of rainy season variability scenarios, they change mixed cropping to mon-cropping system together with the existing mono-cropping, at the same time they change the variety of groundnut and use early maturing variety. Also farmers added that when there is drought or if the rains end early, the groundnut in the mixed system is very difficult to harvest because the soils get too hard. These findings of RPG support the simulation results of SKY-LUDAS in the subsistence farming (using traditional cereals) and the use of groundnut in mono-cropping system as agricultural land-use adaptation strategy.

\subsection{Conclusions}

The study revealed that farmers with good perception of climate change and variability are more into groundnut farming than rice, therefore groundnut farming (especially in mono-cropping) as cash crops is emerged as another land-use adaptation to climate change for farmers in the study area. However, the hypothesis of this finding was not considered at the beginning of this work. This finding was validated by the preliminary results of the game theory implemented for that purpose in the same community. 
Amadou and Villamor, Simulating agricultural land-use adaptation decisions under changing climate...

Acknowledgments: Authors acknowledge the German Federal Ministry of Education and Research, and the West African Science Service Centre on Climate Change and Adapted Land Used (WASCAL) programme.

\section{REFERENCES}

Amadou, M. L. (2015) Simulating agricultural land-use adaptation under changing climate using Multi-Agent System model in the Upper East Region of Ghana. PhD thesis, Kwame Nkrumah University of Science and Technology, Kumasi, Ghana.

Berhan, T., Egziabher, G. \& Edwards, S. (2011) Africa's potential for the ecological intensification of agriculture. In: Climate change and food systems resilience in sub-sahara Africa, 30.

Campbell, B., Sayer, J. A., Frost, P., Vermeulen, S., Pérez, M. R., Cunningham, A. \& Prabhu, R. (2001) Assessing the Performance of Natural Resource Systems 5(2)(22), 24. Retrieved from http://www.consecol.org/vol5/iss2/art22/

Grimm, V., Berger, U., Bastiansen, F., Eliassen, S., Ginot, V., Giske, J., Goss-Custard, J., Grand, T., Heinz, S. K., Huse, G., Huth, A., Jepsen, J. U., Jørgensen, C., Mooij, W. M., Müller, B., Pe’er, G., Piou, C., Railsback, S. F., Robbins, A. M., Robbins, M. M., Rossmanith, E., Rüger, N., Strand, E., Souissi, S., Stillman, R.,Vabø, R., Visser, U., DeAngelis, D. L. (2006). A standard protocol for describing individual-based and agent-based models. Ecol. Modell. 198(1-2), 115-126.

Grimm, V., Berger, U., Deangelis, D. L., Polhill, J. G., Giske, J. \& Railsback, S. F. (2010) The ODD protocol : a review and first update. Ecol. Modell. 221, 2760-2768.

Hageback, J., Sundberg, J., Ostwald, M., Chen, D., Yun, X. \& Knutsson, P. (2005) Climate Variability and Land-use Change in Danangou Watershed, China Examples of Small-Scale Farmers' Adaptation. Clim. Change 72(1-2), 189-212. doi:10.1007/s10584-005-5384-7

Houghton, J. T., Ding, Y., Griggs, D. J., Noguer, M., Linden, P. J. van der, Dai, X., Maskell, K., Johnson, C.A. (2001) Climate change 2001: The scientific basis. Contrib. Work. Gr. I to Third Assess. Rep. Intergov. Panel Clim. Chang. 94.

Lambin, E. F., Geist, H. J. \& Lepers, E. (2003) Dynamics of Land-Use and Land-Cover Change in Tropical Regions. Annu. Rev. Environ. Resour. 28, 205-241.

Le, Q. B., Seidl, R. \& Scholz, R. W. (2012) Feedback loops and types of adaptation in the modelling of land-use decisions in an agent-based simulation. Environ. Model. Softw. 27-28, 83-96.

Le, Q. B., Jin, S. \& Vlek, P. L. G. (2010) Ecological Informatics Land Use Dynamic Simulator ( LUDAS ): A multiagent system model for simulating spatio-temporal dynamics of coupled human - landscape system 2 . Scenariobased application for impact assessment of land-use policies. Ecol. Inform. 5(3), 203-221.

Le, Q. B., Park, J. S., Vlek, P. L. G. \& Cremers, A. B. (2008) Land-Use Dynamic Simulator ( LUDAS ): A multi-agent system model for simulating spatio-temporal dynamics of coupled human - landscape system . I . Structure and theoretical specification. Ecol. Inform. 3, 135 - 153.

Müller, B., Bohn, F., Dreßler, G., Groeneveld, J., Klassert, C. \& Schulze, J. (2013) Describing human decisions in agentbased models - ODD + D , an extension of the ODD protocol. Environ. Model. Softw. 48(0), 37-48.

Schindler, J. (2009) A multi-agent system for simulating land-use and land-cover change in the Atankwidi catchment of Upper East Ghana. Center for Development Research. Bonn, University of Bonn. PhD diss.

Schreinemachers, P. \& Berger, T. (2011) An agent-based simulation model of human-environment interactions in agricultural systems. Environ. Model. Softw. 26, 845-859. doi:10.1016/j.envsoft.2011.02.004

Smit, B., McNabb, D. \& Smithers, J. (1996) Agricultural adaptation to climatic variation. Clim. Change 33, 7-29.

Suphanchaimart, N., Wongsamun, C. \& Panthong, P. (2005) Role-playing games to understand farmers' land-use decisions in the context of cash-crop price reduction in upper northeast Thailand. In: Bousquet, G. Trébuil, B. Hardy (Eds.), Companion Modelling and Multi-agent Systems for Integrated Natural Resource Management in Asia, International Rice Research Institute, Los Baños (Philippine) (2005), pp. 121-139.

Troost, C., Calberto, G., Berger, T., Ingwersen, J., Priesack, E. \& Walter, T. (2012) Agent-based modeling of agricultural adaptation to climate change in a mountainous area of Southwest Germany. Int. Environ. Model. Softw. Soc. 9.

Veldkamp, A. \& Lambin, E. F. (2001) Predicting land-use change. Agric. Ecosyst. Environ. 85, 1-6. Elsevier. Retrieved from http://www.sciencedirect.com/science/article/pii/S0167880901001992

Villamor, G. B. (2012) Flexibility of multi-agent system models for rubber agroforest landscapes and social response to emerging reward mechanisms for ecosystem services in Sumatra, Indonesia. PhD diss., University of Bonn Press, 181. Retrieved from http://hss.ulb.uni-bonn.de/2012/2865/2865.htm

Villamor, G. B., Le, B. Q., Djanibekov, U., Noordwijk, M. Van \& Vlek, P. L. G. (2014) Biodiversity in rubber agroforests , carbon emissions, and rural livelihoods: An agent-based model of land-use dynamics in lowland Sumatra. Environ. Model. Softw. 61, 151-165. Elsevier Ltd. doi:10.1016/j.envsoft.2014.07.013

Villamor, G. B., Noordwijk, M. Van, Troitzsch, K. G. \& Vlek, P. L. G. (2012) Human decision making for empirical agent-based models : construction and validation. Int. Environ. Model. Softw. Soc. 